BMJ Paediatrics Open

\title{
Parental views on attending neonatal intensive care ward rounds
}

Claire Caldwell, ${ }^{1}$ Victoria MacBean, ${ }^{2}$ Katie Hunt, ${ }^{1,3}$ Anne Greenough ${ }^{\oplus 1,3}$

To cite: Caldwell C, MacBean V, Hunt K, et al. Parental views on attending neonatal intensive care ward rounds. BMJ Paediatrics Open 2019;3:e000449. doi:10.1136/ bmjpo-2019-000449

Received 21 January 2019 Revised 13 March 2019 Accepted 20 March 2019

\section{Check for updates}

C Author(s) (or their employer(s)) 2019. Re-use permitted under CC BY-NC. No commercial re-use. See rights and permissions. Published by BMJ.

${ }^{1}$ Department of Women and Children's Health, School of Life Course Sciences, Faculty of Life Sciences \& Medicine, King's College London, London, UK ${ }^{2}$ Department of Clinical Sciences, Brunel University, London, UK

${ }^{3} \mathrm{MRC}$ Centre for Allergic Mechanisms of Asthma, King's College London, London, UK

Correspondence to Professor Anne Greenough; anne.greenough@kcl.ac.uk

\author{
ABSTRACT \\ Objectives To ascertain parental views regarding taking \\ part in neonatal unit ward rounds. \\ Design A service evaluation project. \\ Setting Tertiary neonatal intensive care unit. \\ Patients Parent(s) of infants receiving care on the \\ neonatal unit.
}

Interventions Structured interviews conducted at the cot side.

Main outcome measures Parents were asked if they knew when ward rounds occurred, whether they had attended ward rounds and if they had not what were the factors inhibiting them from doing so, their experience of attending ward rounds and whether they were concerned about issues of confidentiality.

Results 23 of 24 consecutive parents agreed to be interviewed. The median age of their infants was 14 (range 3 -123) days when they were interviewed. Eighty-five per cent were able to identify when a nursing handover or doctor's ward round occurred. Seventy-five per cent of parents had attended at least one ward round and the median score in terms of usefulness was 5 out of 5. Reasons for not attending included time and cost to travel to the unit, their partners were working and having other children. Parents volunteered that the nurses proactively updated them as soon as they arrived, hence making regular attendance less important. Regarding confidentiality, $85 \%$ were not concerned if other people overheard information about their baby, unless the news was bad.

Conclusions Parents recognised the value of attending ward rounds and generally found it a positive experience, but emphasised limitations on their ability to attend.

\section{INTRODUCTION}

Models of delivering neonatal intensive care are changing, with a move towards more family-centred care. ${ }^{1}$ An example includes allowing unrestricted access to replace visiting times. Guidelines published by the American Society of Critical Care Medicine ${ }^{2}$ incorporated a systematic literature review of the presence of family members on ward rounds in all intensive care settings: adult, paediatric and neonatal. They suggested that family members be offered the opportunity to participate in ward rounds, "to improve satisfaction with communication and increase family engagement'. An analysis of practice across UK neonatal units undertaken in 2010
What is already known on this topic?

There is an increasing focus on the need to provide family-centred care.

- On neonatal units, this may involve unrestricted access and parents attending ward rounds.

\section{What this study adds?}

In-depth interviews were undertaken to ascertain parents' views about attending neonatal unit ward rounds.

- The majority had attended at least one ward round and had a positive experience, but reported other sources of information.

- Distance and cost of travel, partners at work and other siblings were reported as difficulties regarding attendance.

found that in $86 \%$ of units, parents were present during ward rounds. ${ }^{3}$ Forty-seven per cent allowed parents for the whole round and $39 \%$ only when their baby was being discussed. Our unit encourages parents to attend the consultant ward rounds, but only when their baby was being discussed to maintain confidentiality. The National Neonatal Audit Programme is incorporating a measure of parents attending ward rounds; hence, it is important that the positives and problems of such a measure are well understood. The aims of this study, therefore, were to ascertain parent(s) experience of attending ward rounds, the problems of doing so, whether they had any concerns about the confidentiality of all parents attending the ward rounds and what other sources of information about neonatal care they used.

\section{METHODS}

A service evaluation project was undertaken. One interviewer approached parents of infants on the neonatal intensive care unit at King's College Hospital NHS Foundation Trust between June and August 2017. Information regarding the timing of the ward 
rounds and visiting policy was given to parents verbally on admission and included in the admission pack of information. Funding was available for those in need to travel to the neonatal unit and onsite accommodation available for those who lived outside London.

If parent(s) gave consent, a structured interview was conducted at the cot side. The questions were grouped as follows: demographic data, information received about the ward rounds, attendance at ward rounds and their experience were there issues of confidentiality and what other sources of information about neonatal care were used. In addition, information about their time and cost to travel to the unit and any other issues which restricted their attendance at ward rounds was collected. The answers were transcribed at the cot side by the interviewer. Parents were asked to rank the usefulness of attending ward rounds on a Likert scale of 1-5. Other than demographic data, there was a mixture of open (What was your experience of the ward round?) and closed (Would you like to be present on every ward round) questions. Answers were collected in a themed analysis of parental knowledge and experience of ward rounds, confidentiality of medical information, information sharing between parents and the internet as a source of information. There was an opportunity for parents to add their own comments at the end of the interview.

\section{Patient and public involvement statement}

Views from parents on the neonatal unit (NU) as to whether the topic was important were sought and they were involved in the design of the questionnaire.

\section{RESULTS}

\section{Respondents}

In all, 24 parents of 20 infants were consecutively approached and 23 agreed to be interviewed. The median age of their babies was 14 (range 3-123) days and their median duration on the unit was 10 (range 3-123) days. The median age of the interviewees was 32 (range 23-42) years. Three mother/father pairs, one father and 16 mothers were interviewed. For mother/father pairs, the responses were combined; thus, there were 20 'responses'. Four interviewees were resident in hospital accommodation and two were inpatients on the postnatal ward, the others were visiting their infants from home

\section{Experience of ward rounds}

Seventeen $(85 \%)$ of respondents were able to identify when a nursing or doctors' handover or consultant's ward round occurred. In total, $15(75 \%)$ of parents had attended at least one ward round during the admission; 19 (95\%) of respondents scored their experience of being on the ward rounds as useful, with a median score of 5 out of 5 . In all, $18(90 \%)$ of parents stated they would like to attend at least one ward round per day. Two parents said they did not want to attend ward rounds, but one had been told not to come to ward rounds and the other was under the impression they were not allowed on ward rounds. Parents recognised the purpose of the ward round was to review their baby's clinical course and make a plan for the day. One parent, however, found it worrying to hear 'scary things', but was reassured by the consultant updating her at the end of the discussion. Parents appreciated a 'one-to-one update from the doctor'. Some felt they could 'ask questions and contribute'. They stated that they 'didn't feel excluded because doctors would often introduce themselves first'. Other parents were more intimidated, 'I wanted to ask questions but couldn't' and one felt there was a lack of feedback, 'people come in and look at the charts, but don't tell me what was happening'. Another parent appreciated the opportunity to input into her baby's care and reported that when her baby was unwell, the consultant took time to listen to her observations.

\section{Difficulties in attending ward rounds}

Difficulties in attending ward rounds included travel cost and time, other children and partners being at work. In all, 14 mothers were travelling to the unit at a cost of $£ 0-£ 19.80$ per journey with journey times from $15 \mathrm{~min}$ to 2.5 hours; ten respondents (50\%) had a journey cost of over $£ 5$ and a journey time of greater than $30 \mathrm{~min}$. In all, 11 respondents $(55 \%)$ had other children at home and nine had partners who had returned to work.

\section{Confidentiality}

Parents were asked, "Are you concerned about other parents attending ward rounds hearing confidential information about you and your baby?" In total, 17 (85\%) were 'not bothered', 'not worried' or 'not concerned'. An example comment was, 'Not really bothered, everyone is just focused on their own baby'. Two parents, however, stated that if the news was bad, they would not want other people to overhear it.

\section{Other sources of information}

Many parents expressed their appreciation that nurses proactively updated parents as soon as they arrived on the unit. Totally, 18 parents had spoken to at least one other parent on the unit, all had found it helpful to discuss their experiences, especially with 'longer-term mums'. In all, $14(70 \%)$ had used the internet to obtain more information, with search terms such as prematurity, survival rates, developmental outcomes by gestational age and discharge dates. Medical terms were frequently searched: necrotising enterocolitis, patent ductus arteriosus, continuous positive airway pressure, jaundice, medical equipment such as ventilators and medication names. Other local neonatal units were also researched by parents. Specific parent forums were only used by five $(25 \%)$ of those interviewed.

\section{DISCUSSION}

We have demonstrated that the majority of parents surveyed had attended at least one ward round and had generally found it a positive experience. We feel our results are representative as only one of the consecutive parents who was approached declined to take part. A strength 
of our study was that the researcher was able to conduct in-depth interviews resulting in a wealth of responses. A survey of parents in a tertiary neonatal unit in Liverpool carried out in $2005^{4}$ found that parents had mixed views on attending the ward rounds and the authors concluded parental communication with the clinical team was probably best conducted outside of the ward round itself. A more recent study ${ }^{5}$ allocated parents to attendance or non-attendance of ward rounds, followed by a cross over to the other arm of the trial after a washout period. Ninety-five per cent of parents who completed the trial believed that parents should be allowed to attend ward rounds. This corresponds to the results of our study with $18(90 \%)$ of parents attending at least one ward round.

There might, however, be negative effects on parents due to the perceived stress of attending ward round. In one study, 'stress' was compared in parents of babies who had attended ward rounds to those who had not. Importantly, there was no significant difference in scores using the Parent Stressor Scale between the two groups. ${ }^{6}$ In a paediatric intensive care unit (PICU) setting, ${ }^{7}$ it was found that race, educational level, age of the family member, age of the child, whether the admission was expected and whether the family member was a medical professional had no association with whether the family member attended rounds. The only factor associated with a higher likelihood of attending rounds was a family's stated preference for doing so (OR 3.4). We have identified multiple reasons why parents may not be able to attend and these need to be taken into account in any outcome measure.

In a paediatric inpatient unit, interviewing 18 sets of parents after their participation in ward rounds ${ }^{8}$ revealed their overall experience was positive. The important outcomes to parents included being able to communicate with the team, understanding the plan of care and participation in decision-making. ${ }^{8}$ A unit where parents were excluded from the ward rounds surveyed the strengths and weaknesses in parent-staff communication over the course of a year. ${ }^{9}$ They found parents were generally satisfied with the communication they had with both nurses and doctors. Some parents, however, commented that if their child was not very unwell, they did not talk to the doctors as much as they would have liked. They recognised the time pressure the medical team were under, but wanted acknowledgement that the admission of any baby to a neonatal unit, no matter how 'well', is extremely stressful for the family. In our study, we highlight parents found the nurses looking after their baby an important source of information.

Although we found that the majority of parents would like to attend the ward rounds, it cannot be assumed that all healthcare professionals (HCPs) want to be involved in family-centred rounds (FCRs). Stickney et $a l^{10}$ investigated the differences between HCPs and parents regarding experiences and attitudes towards participation in morning rounds. A cross-sectional study was undertaken of 100 parents and 131 HCPs in a tertiary PICU setting. Similar to other studies, 92\% of parents expressed a desire to attend the rounds, but only $54 \%$ of HCPs reported a preference for parental presence on ward rounds. ${ }^{10}$ Furthermore, only $30 \%$ of HCPs perceived that parents would understand the format, $73 \%$ of parents reported that they did. HCPs in a survey of HCPs in French neonatal units ${ }^{11}$ expressed concerns about parents attending ward rounds; they were worried about longer duration of ward rounds, fewer opportunities for teaching and increased stress for parents and HCPs. The more experienced respondents, however, were much less likely to consider these concerns a barrier to implementing parental presence on ward rounds. A study in a tertiary neonatal unit in Canada, ${ }^{12}$ however, found that nurses were more likely than medical trainees to support parental presence at rounds. Trainees had concerns regarding a decreased level of teaching when parents were present. In a PICU setting, trainees also reported feeling less comfortable being questioned at the bedside compared with in a conference room. ${ }^{13}$ Parents, however, rated the trainees taking part in the bedside case presentations as more competent than when the trainees presented separately in the conference room. Possible advantages for doctors in training expressed were the increased opportunities to observe senior doctors communicating with patients and families and also to have their own skills evaluated. Osorio et $a l^{14}$ found FCRs provided an enhanced environment for the assessment of communication skills by seniors and also an opportunity for feedback from members of the multidisciplinary team. Prior to the introduction of FCR in their neonatal unit, Voos $e t a l^{15}$ surveyed parents and HCPs and repeated the surveys 6 months after the introduction of FCR. Parents' satisfaction scores increased significantly $(\mathrm{p}<0.01)$ regarding communication, meeting with physicians and obtaining information about their infants. The main members of staff communicating with parents on their unit were neonatal nurse practitioners and fellows and they reported increased collaboration and satisfaction with care decisions. ${ }^{15}$ FCRs were introduced in one acute care unit in Cinncinati Children's Hospital, but spread throughout the departments as teams saw the benefits conferred. ${ }^{16}$ The initial concerns of longer duration of ward rounds and less teaching were addressed. Efficient use of the ward round time counterbalanced the longer duration by having less paperwork and parental updates to do after the ward round was finished. Teaching style was adapted and the advantage of learning bedside communication skills was felt to be beneficial.

In conclusion, our study demonstrates that parents recognise the importance of the ward round within the context of receiving information about their baby. The majority of parents would like the opportunity to attend, but there are important limitations to their attending including travel time and other siblings. Furthermore, it is important that there is appropriate communication with parents regarding attendance at ward rounds. These 
need to be factored in when developing any criteria for standard of care.

Contributors AG conceived the study; CC collected the data; all of the authors were involved in the analysis; CC wrote the initial draft and all authors were involved in the production of the final manuscript and approved its content.

Funding The research was supported by the National Institute for Health Research (NIHR) Biomedical Research Centre based at Guy's and St Thomas' NHS Foundation Trust and King's College London.

Disclaimer The views expressed are those of the author(s) and not necessarily those of the NHS, the NIHR or the Department of Health.

Competing interests None declared.

Patient consent for publication Not required.

Provenance and peer review Not commissioned; externally peer reviewed.

Data sharing statement We agree to data sharing on request.

Open access This is an open access article distributed in accordance with the Creative Commons Attribution Non Commercial (CC BY-NC 4.0) license, which permits others to distribute, remix, adapt, build upon this work non-commercially, and license their derivative works on different terms, provided the original work is properly cited, appropriate credit is given, any changes made indicated, and the use is non-commercial. See: http://creativecommons.org/licenses/by-nc/4.0/.

\section{REFERENCES}

1. Committee on Hospital care and institute for patient- and family-centered care. Patient- and family-centered care and the pediatrician's role. Pediatrics 2012;129:394-404.

2. Davidson JE, Aslakson RA, Long AC, et al. Guidelines for FamilyCentered care in the neonatal, pediatric, and adult ICU. Crit Care Med 2017;45:103-28.

3. Redshaw ME, StC Hamilton KE, POPPY Project Research Team. Family centred care? facilities, information and support for parents in UK neonatal units. Arch Dis Child Fetal Neonatal Ed 2010;95:F365-F368.
4. Bramwell R, Weindling M, Team FR, FVWR Research Team. Families' views on ward rounds in neonatal units. Arch Dis Child Fetal Neonatal Ed 2005;90:F429-F431.

5. Abdel-Latif ME, Boswell D, Broom M, et al. Parental presence on neonatal intensive care unit clinical bedside rounds: randomised trial and focus group discussion. Arch Dis Child Fetal Neonatal Ed 2015;100:F203-9.

6. Gustafson KW, LaBrecque MA, Graham DA, et al. Effect of parent presence during multidisciplinary rounds on NICU-related parental stress. J Obstet Gynecol Neonatal Nurs 2016;45:661-70.

7. Drago MJ, Aronson PL, Madrigal V, et al. Are family characteristics associated with attendance at family centered rounds in the PICU? Pediatr Crit Care Med 2013;14:e93-7.

8. Latta LC, Dick R, Parry C, et al. Parental responses to involvement in rounds on a pediatric inpatient unit at a teaching hospital: a qualitative study. Acad Med 2008;83:292-7.

9. Wigert H, Dellenmark MB, Bry K. Strengths and weaknesses of parent-staff communication in the NICU: a survey assessment. BMC Pediatr 2013;13.

10. Stickney CA, Ziniel SI, Brett MS, et al. Family participation during intensive care unit rounds: attitudes and experiences of parents and healthcare providers in a tertiary pediatric intensive care unit. $J$ Pediatr 2014;164:402-6.

11. Thébaud V, Lecorguillé M, Roué J-M, et al. Healthcare professional perceptions of family-centred rounds in French NICUs: a crosssectional study. BMJ Open 2017;7:e013313.

12. Grzyb MJ, Coo H, Rühland L, et al. Views of parents and healthcare providers regarding parental presence at bedside rounds in a neonatal intensive care unit. J Perinatol 2014;34:143-8.

13. Landry M-A, Lafrenaye $\mathrm{S}$, Roy $\mathrm{M}-\mathrm{C}$, et al. A randomized, controlled trial of bedside versus conference-room case presentation in a pediatric intensive care unit. Pediatrics 2007;120:275-80.

14. Osorio SN, Ward MJ, Siew L, et al. Assessment of pediatric residents' communication and interpersonal skills during familycentered rounds. Hosp Pediatr 2012;2:85-92.

15. Voos KC, Ross G, Ward MJ, et al. Effects of implementing familycentered rounds (FCRs) in a neonatal intensive care unit (NICU). $J$ Matern Fetal Neonatal Med 2011;24:1403-6.

16. Muething SE, Kotagal UR, Schoettker PJ, et al. Family-centered bedside rounds: a new approach to patient care and teaching. Pediatrics 2007;119:829-32. 